\title{
Morbidity Profile, Healthcare Utilization and Associated out of Pocket Expenditure on Health among Elderly Population of Lucknow District, Northern India
}

Shivendra K Singh ${ }^{1}$ and Pavan Pandey ${ }^{2^{*}}$

${ }^{1}$ Department of Community Medicine, King George Medical University, Lucknow, Uttar Pradesh, India

${ }^{2}$ Department of Community Medicine \& Public Health, King George Medical University, Lucknow, Uttar Pradesh, India

"Corresponding author: Dr. Pavan Pandey, Junior Resident, Department of Community Medicine \& Public Health, King George Medical University, Lucknow, Uttar Pradesh, India, Tel: 0522225 7540; E-mail: dnameispaone@gmail.com

Received date: March 30, 2016; Accepted date: May 10, 2016; Published date: May 16, 2016

Copyright: (C) 2016 Singh SK, et al. This is an open-access article distributed under the terms of the Creative Commons Attribution License, which permits unrestricted use, distribution, and reproduction in any medium, provided the original author and source are credited.

\section{Abstract}

Objective: To study and assess the morbidities occurring in an elderly person, the pattern of their healthcare utilization and the expenditure they incur during the process of receiving treatment.

Methods: A cross-sectional study was carried out involving 404 elderly participants from both the urban and rural parts of Lucknow. The elderly participants were interviewed with the help of a pretested questionnaire. The data was collected on morbidity profile, healthcare utilization and associated expenditure by elderly.

Results: Most common single chronic disease entity was hypertension $(20.5 \%)$, and the most common group of morbidities were dental $(18.8 \%)$, orthopedics $(17.3 \%)$ and cardiovascular $(11.8 \%)$ in that order. The proportion of those utilizing Inpatient care, out-patient care, Outpatient dental care, AYUSH care and self-medication was $32.9 \%$, $62.9 \%, 20.7 \%, 36.4 \%$ and $35.6 \%$ respectively. Total mean out of pocket expenditure on health among participants from the urban and rural area was INR 7842.25 (SD 9067.97) and INR 6034.82 (SD 9566.45) respectively.

Conclusion: The out of pocket expenditure among the elderly was much higher than per capita health expenditure of the country.

Keywords: Elderly; Morbidity; Healthcare utilization; Expenditure

\section{Introduction}

Someone has very rightly described old age as an incurable disease. With this in mind, World Health Organization (WHO) in the year 2012 celebrated world health day with the theme "Good health adds year to life" [1]. The stress was to promote healthy aging. The government of India launched its national policy for older people in the year 1999; this was after WHO declared the year 1999 as the international year for elderly. The policy defines "senior citizen or elderly" as a person who is of age 60 years or above. This policy was amended in the year 2011[2]. According to a United Nation's 2013 report, the proportion of the elderly in the world is continuously increasing; it was $8.1 \%$ and $11.7 \%$ in the year 2000 and 2013 respectively, and it is expected to be about 21.2 percent by the year 2030. The same report also mentions that the proportion of the elderly in India was about 7.2 percent in the year 2000, and it increased to 8.3 percent in the year 2013, and it is expected to be 10.9 percent in the year 2030 [3]. According to the Sample Registration System (SRS) 2012 the proportion of the elderly in India was $8.3 \%$ with females constituting $8.6 \%$ and males $7.9 \%$, whereas in Uttar Pradesh proportion of the elderly was $7.1 \%$ [4].

Every age group has its unique, set of health problems as an infant and young children have their set of diseases, an elderly have set of diseases of their own. The various changes that accompanies the process of aging, leads to an array of illness among older people. Various studies and surveys conducted all over India [5,6], Uttar Pradesh and Lucknow [7] have studied the morbidities occurring in elderly.

To regain their lost health status the elderly must seek the treatment. India has an array of a different system of medicines. Along with modern medicine (allopathic), Indian people also use Indian/ alternative system of medicine. This alternative system of medicine includes Ayurveda, Yoga, Unani, Siddha \& Homeopathy; more popularly known by an acronym AYUSH. There is a separate minister of AYUSH under the ministry of health and family welfare, in the government of India [8].

Out of pocket (OOP) health expenditure is any amount of money spent by a person whose primary intent is to contribute to the restoration or enhancement of the health status. It is a part of private expenditure from persons own pocket. This spending represents the share of the expenses that the insured party must pay directly to the healthcare provider without a third-party (insurer, or state) [9].

India is among countries where more than $50 \%$ of spending on health comes from out of pocket. In fact in WHO southeast region the out of pocket expenditure on health was third highest in India, next to Myanmar and Bangladesh. Even countries like Nepal, Sri Lanka, Bhutan, and Pakistan are doing much better than India in this respect [10]. According to national health accounts, 2004-2005 of the total expenditure on health in India contribution from the private sector 
was $78.05 \%$ [11]. Of the total $78.05 \%$ contribution from the private sector, household contribution in the form of out of pocket expenditure was $71.09 \%$. These figures point out that primary source of spending on health is from out of pocket expenses [11].

Many studies were conducted earlier to find the out of pocket expenditure on health in India, but only a few of them have considered health spending specifically by elderly. In the given background we carried this study with the objective of study the morbidity profile, healthcare utilization and associated out of pocket expenditure on health by the geriatric population of Lucknow district.

\section{Methods}

\section{Study setting}

Present study is a part of master's degree dissertation to investigate the interaction of an elderly person with the health system.

Present study: This was a community-based cross-sectional study carried out in the Lucknow district, which is the capital of the state of Uttar Pradesh, the most populous state in India.

Study duration: The total duration of the study was one year from August 2013 to July 2014

Study participants: Person 60 years and older (definition of the elderly by the government of India).

Source population: All the elderly residing in the urban and rural parts of Lucknow district.

Inclusion criteria: elderly able to answer the questions/ interview and the elderly who gave valid informed consent for the study.

Exclusion criteria: Uncooperative person, an elderly person who cannot complete/answer the questions/interview, the elderly who did not consent for the study.

Sampling technique: The study employed multi-stage random sampling technique [7]. As per Sample Registration System - 2012 (SRS), the proportion of the elderly in Uttar Pradesh residing in urban and rural areas was about $49.0 \%$ and $51.0 \%$ respectively [13].

Stage-I: We collected 198 (49\%) study subject from an urban area and 206 study participants (51\%) from the rural area. Chief election commission of India has divided the Lucknow district into nine assembly constituency (legislative assembly no. 168-176) out of which five constituencies (171-175) cover the urban areas of Lucknow district and rest four $(168-170,176)$ includes the rural parts of Lucknow district. A complete list of all people who are 18 years age and older (eligible voter) in each polling booth is available on the website of the chief election commission of Uttar Pradesh [14].

Stage II: Selection of study subject from urban areas of Lucknow; Of the five assembly constituencies in urban Lucknow, 40 elderly were selected from first four assembly constituency and 38 study participants have been chosen from the last assembly constituency. Thus, a total of 198 required study participants were collected from urban areas.

Stage -III Urban: From each urban assembly constituency, ten polling booths were selected randomly.

Stage IV: Then from each polling station, four study participants have been chosen. From the last polling station of the last assembly constituency (assembly constituency no. 175) we selected only two study participants. Stage II - Selection of study subject from rural areas of Lucknow: Rural Lucknow is covered by four assembly constituency. So 52 study participants were selected from first three constituencies and 50 study participants had been chosen from the last assembly constituency. Thus, a total of 206 study participants were selected from a rural area.

Stage III rural: From each rural constituency, 13 polling booths were selected randomly.

Stage IV: We selected four elderly from each voting booth by simple random sampling. From last polling booth of the last assembly constituency (constituency no. 176), we selected only two study participants (total 50).

Stage V: Selection of elderly from polling station/booth: From the list of all eligible voters of selected polling station/booth 20 elderly were shortlisted by simple random sampling technique. When approached to an elderly in the community, the identity of the individual was confirmed by voter identification card that she/he possessed. After verification if an elderly fit in our inclusion criteria, then the further interview was conducted. Otherwise, the next individual from the list was approached and so on. This procedure was followed till the requisite numbers of the elderly were interviewed from a given polling station. To cover the requisites sample of 404 we approached a total of 463 elderly in the community. Sample size: Assuming that 50 percent of the households which has an at least one elderly, made a healthcare out of pocket expenditure within last six months [12]. Applying to this estimate a confidence level of 95 percent, precision level of 5 percent, and a non-response rate of 10 percent, the sample size of 404 arrived.

Data collection: The schedule 60_25.0 utilized by NSSO for their survey titled 'Morbidity and Health Care' from January to June 2004 was studied in detail [15]. A pre-structured questionnaire was then prepared; later the same was mailed to experts in the field of assessing out of pocket expenditure. Suggestion and rectification were included in the final version of the questionnaire. The questionnaire was then translated from English into Hindi (native language). The questionnaire was pretested on a sample of 30 elderly, 15 from the community and 15 from the elderly admitted to the ward and visiting the out-patient department of Gandhi Memorial hospital. Pretesting was carried out to check whether questionnaire covered all aspect of healthcare utilization, health expenditure and to test the precision of responses. The results of pretest were excluded from final analysis.

The study questionnaire had four components i) socio-demographic ii) health status of an elderly iii) household income and expenditure and iv) healthcare utilization, healthcare spending \& source of financing, etc. Total healthcare spending consisted of following three components self-medication expenditure for past one month, outpatient care expenditure for past three months and in-patients care for past six months. Questions were asked about illnesses episodes and whether the sick elderly availed healthcare or eschewed it. For treated illness episodes, data was amassed on expenditures incurred as (i) direct medical expenditures, like doctor's fees, medicines, investigations, procedures/surgery, hospital charges (ii) indirect medical costs like transport, expenditure on escort and food during the period of stay. Wherever possible the expenditures as mentioned by the elderly were cross-checked with the bills of hospital/ prescription slip etc., but this was not feasible in every case. All expenses were calculated in Indian National Rupee (INR- the currency of India). 
Citation: $\quad$ Singh SK, Pandey P (2016) Morbidity Profile, Healthcare Utilization and Associated out of Pocket Expenditure on Health among Elderly Population of Lucknow District, Northern India . Trop Med Surg 4: 210. doi:10.4172/2329-9088.1000210

Page 3 of 6

Total medical expenditure was computed by summing direct as well as the indirect medical cost. All forms of healthcare expenditures weather of modern medicine, dental, physiotherapy, Ayurveda, traditional healers and buying medical aid were included to estimate total healthcare out of pocket expenditure. When the source of financing was insurance, the net amount paid by the insurance company was deducted to calculate net out of pocket payment made by elderly.

\section{Results}

Health status, health seeking behavior and health related expenditure is influenced by the social and demographic variables of the study participants. Table 1 provides details of the various demographic variables of study participants. Most of the elderly $(56.4 \%)$ were in age group $60-<70$ years and Hinduism $(66.1 \%)$ was most common religion. Most of the study participants were still married. Most of the elderly had one or other type of addiction habit (58.9\%).

Table 2 shows the proportion of the elderly having one or more chronic disease was $56.9 \%$. Most frequent single chronic disease entity among all subjects was hypertension (20.5\%), followed by diabetes $(17.3 \%)$ and cataract (11.4\%). Most common group of morbidities were dental (18.8\%), orthopedics (17.3\%) and cardiovascular $(11.8 \%)$ in that order.

\begin{tabular}{|c|c|c|c|c|c|c|}
\hline \multirow{2}{*}{ Bio-Social Characteristics } & \multicolumn{2}{|c|}{ Urban } & \multicolumn{2}{|c|}{ Rural } & \multicolumn{2}{|c|}{ Total } \\
\hline & $\begin{array}{c}\text { Male } \\
\mathrm{n}=99(\%)\end{array}$ & $\begin{array}{c}\text { Female } \\
n=99(\%)\end{array}$ & $\begin{array}{c}\text { Male } \\
n=92(\%)\end{array}$ & $\begin{array}{c}\text { Female } \\
\mathrm{n}=114(\%)\end{array}$ & $n=404$ & $\%$ \\
\hline \multicolumn{7}{|l|}{ Age Group(years) } \\
\hline $60->70$ & $55(55.6)$ & $58(58.6)$ & $51(55.4)$ & $64(56.1)$ & 228 & 56.4 \\
\hline $70-<0$ & $32(32.3)$ & $31(31.3)$ & $34(36.9)$ & $40(35.0)$ & 137 & 33.9 \\
\hline$\geq 80$ & $12(12.1)$ & $10(10.1)$ & $7(7.6)$ & $10(8.9)$ & 39 & 9.7 \\
\hline \multicolumn{7}{|l|}{ Religion } \\
\hline Hindu & $65(65.7)$ & $63(63.6)$ & $54(58.7)$ & $85(74.6)$ & 267 & 66.1 \\
\hline Muslim & $30(30.3)$ & $34(34.3)$ & $38(41.3)$ & $29(25.4)$ & 131 & 32.4 \\
\hline Sikh & $4(4.0)$ & $2(2.0)$ & $0(0.0)$ & $0(0.0)$ & 6 & 1.5 \\
\hline \multicolumn{7}{|l|}{ Marital Status } \\
\hline Unmarried & $1(1.0)$ & $0(0.0)$ & $2(2.2)$ & $0(0.0)$ & 3 & 0.7 \\
\hline Married & $63(63.6)$ & $75(75.8)$ & $67(72.8)$ & $82(71.9)$ & 287 & 71 \\
\hline Widow/Widower & $32(32.3)$ & $23(23.2)$ & $18(19.6)$ & $27(23.7)$ & 100 & 24.8 \\
\hline Divorce/Separated & $3(3.0)$ & $1(1.0)$ & $5(5.4)$ & $5(4.4)$ & 14 & 3.4 \\
\hline \multicolumn{7}{|l|}{ Living arrangement } \\
\hline Spouse\& children & $38(38.4)$ & $37(37.4)$ & $44(47.8)$ & $50(43.9)$ & 169 & 41.8 \\
\hline Only Children & $20(20.2)$ & $29(29.3)$ & $22(23.9)$ & $26(22.8)$ & 97 & 24 \\
\hline Only with Spouse & $29(29.3)$ & $30(30.3)$ & $20(21.7)$ & $29(25.4)$ & 108 & 26.7 \\
\hline Living alone & $2(2.0)$ & $0(0.0)$ & $0(0.0)$ & $0(0.0)$ & 2 & 0.5 \\
\hline Relative & $10(10.1)$ & $3(3.0)$ & $6(6.5)$ & $9(7.8)$ & 28 & 5.4 \\
\hline \multicolumn{7}{|l|}{ Educational qualification } \\
\hline Illiterate & $9(9.0)$ & $14(14.1)$ & $12(13.0)$ & $15(13.2)$ & 50 & 12.37 \\
\hline Just literate & $23(23.2)$ & $15(15.1)$ & $26(28.3)$ & $11(9.6)$ & 75 & 18.6 \\
\hline Up to primary & $8(8.0)$ & $30(30.3)$ & $13(14.1)$ & $51(44.7)$ & 101 & 25 \\
\hline Up to12 & $22(22.2)$ & $16(16.1)$ & $7(7.6)$ & $31(27.2)$ & 76 & 18.8 \\
\hline Graduate/diploma & $24(22.2)$ & $13(13.1)$ & $22(23.9)$ & $4(3.5)$ & 64 & 15.8 \\
\hline Post-graduate \& above & $13(13.1)$ & $11(11.1)$ & $12(13.04)$ & $2(1.8)$ & 38 & 8.9 \\
\hline
\end{tabular}


Citation: $\quad$ Singh SK, Pandey P (2016) Morbidity Profile, Healthcare Utilization and Associated out of Pocket Expenditure on Health among Elderly Population of Lucknow District, Northern India . Trop Med Surg 4: 210. doi:10.4172/2329-9088.1000210

Page 4 of 6

\begin{tabular}{|l|l|l|l|l|l|l|}
\hline Addiction & $67(67.7)$ & $18(18.2)$ & $56(60.9)$ & $36(31.6)$ & 238 & 58.9 \\
\hline Yes & $32(32.3)$ & $81(81.8)$ & $36(39.1)$ & $78(68.4)$ & 166 & 41.1 \\
\hline No &
\end{tabular}

Table 1: Biosocial characteristic of the elderly by their residential status and gender $(\mathrm{n}=404) \mathrm{z}$.

\begin{tabular}{|c|c|c|c|c|c|c|}
\hline \multirow{3}{*}{$\begin{array}{l}\text { Type } \\
\text { Morbidity\# }\end{array}$} & \multicolumn{2}{|l|}{ Urban } & \multicolumn{2}{|l|}{ Rural } & \multicolumn{2}{|l|}{ Total } \\
\hline & \multicolumn{2}{|r|}{ Female } & \multicolumn{2}{|r|}{ Female } & \multirow{2}{*}{$n=404$} & \multirow{2}{*}{$\%$} \\
\hline & $\mathrm{n}=99(\%)$ & $\begin{array}{l}n=99 \\
(\%)\end{array}$ & $n=92(\%)$ & $\begin{array}{l}n=114 \\
(\%)\end{array}$ & & \\
\hline \multicolumn{7}{|l|}{ Type of illness } \\
\hline Acute\$ & $20(20.2)$ & $28(28.3)$ & $22(24.0)$ & $23(20.2)$ & 93 & 23 \\
\hline Chronic\$\$ & $52(52.5)$ & $56(56.6)$ & 49 (53.3) & $73(64.0)$ & 230 & 57 \\
\hline \multicolumn{7}{|c|}{ Three most common Chronic diseases } \\
\hline Diabetes mellitus & $14(14.1)$ & $18(18.2)$ & $18(19.6)$ & $20(17.5)$ & 70 & 17 \\
\hline Hypertension & $26(26.3)$ & $21(21.2)$ & $20(21.7)$ & $16(14.0)$ & 83 & 21 \\
\hline Cataract & $13(13.1)$ & $9(9.0)$ & $7(7.6)$ & $17(15.0)$ & 46 & 11 \\
\hline \multicolumn{7}{|c|}{ System Wise morbidity Profile } \\
\hline Orthopedics & $12(12.1)$ & $18(18.2)$ & $14(14.1)$ & $26(22.8)$ & 70 & 17 \\
\hline Neurological & $3(3.0)$ & $2(2.0)$ & $3(3.3)$ & $3(2.6)$ & 11 & 2.7 \\
\hline Respiratory & $8(8.0)$ & $3(3.0)$ & $5(5.4)$ & $3(2.6)$ & 19 & 4.7 \\
\hline Cardiovascular & $13(13.1)$ & $11(11.1)$ & $14(15.2)$ & $10(8.8)$ & 48 & 12 \\
\hline Gastrointestinal & $2(2.0)$ & $0(0.0)$ & $5(5.4)$ & $0(0.0)$ & 7 & 1.7 \\
\hline Renal & $6(6.0)$ & $0(0.0)$ & $3(3.3)$ & $4(3.5)$ & 13 & 3.2 \\
\hline Psychiatric & $6(6.0)$ & $8(8.0)$ & $9(9.8)$ & $7(6.1)$ & 30 & 7.4 \\
\hline ENT & $2(2.0)$ & $5(5.0)$ & $10(10.9)$ & $9(7.9)$ & 26 & 6.4 \\
\hline Ophthalmology & $8(8.0)$ & $10(10.1)$ & $11(12.0)$ & $7(6.1)$ & 36 & 8.9 \\
\hline Urogenital & $3(3.0)$ & $1(1.0)$ & $1(1.1)$ & $0(0.0)$ & 5 & 1.2 \\
\hline Malignancy & $3(3.0)$ & $1(1.0)$ & $0(0.0)$ & $0(0.0)$ & 4 & 1 \\
\hline Dental & $17(17.2)$ & $21(21.2)$ & $15(16.3)$ & $23(20.2)$ & 76 & 19 \\
\hline Others & $5(5.0)$ & $3(3.0)$ & $6(6.5)$ & $1(0.9)$ & 15 & 3.7 \\
\hline $\begin{array}{l}\text { \#- multiple respon } \\
>30 \text { days }\end{array}$ & ; \$- tak & & $r<30 \mathrm{da}$ & & & for \\
\hline
\end{tabular}

\begin{tabular}{|c|c|c|c|c|}
\hline \multirow[t]{2}{*}{ Healthcare services\# } & \multirow[t]{2}{*}{$\begin{array}{l}\text { Urban } \\
n=198\end{array}$} & \multirow[t]{2}{*}{$\begin{array}{c}\text { Rural } \\
n=206\end{array}$} & \multicolumn{2}{|c|}{$\begin{array}{c}\text { Total } \\
(n=404)\end{array}$} \\
\hline & & & $\mathbf{n}$ & $\%$ \\
\hline $\begin{array}{l}\text { In-patient care (during previous } 6 \\
\text { month) }\end{array}$ & 76 & 57 & 133 & $(32.9)$ \\
\hline $\begin{array}{l}\text { Out-patient Medical care (during } \\
\text { previous } 3 \text { month) }\end{array}$ & 142 & 112 & 254 & $(62.9)$ \\
\hline $\begin{array}{l}\text { Out-patient dental (during previous } 3 \\
\text { month) }\end{array}$ & 53 & 31 & 84 & $(20.7)$ \\
\hline AYUSH (during previous 3 month) & 64 & 83 & 147 & $(36.4)$ \\
\hline $\begin{array}{l}\text { Self-medication } \\
\text { month) }\end{array}$ & 64 & 80 & 144 & $(35.6)$ \\
\hline Medical aid (during previous 6 month) & 40 & 17 & 57 & $(14.1)$ \\
\hline
\end{tabular}

Table 3: Different types of Healthcare services availed by the elderly $(n=404)$.

Table 4 shows the total mean OOP expenditure on health among participants from urban and rural area was INR 7,842.25 (SD 9067.97) and INR 6,034.82 (SD 9566.45) respectively. In urban as well as rural area major chunk of this total expenditure is constituted by in-patient care and least burden due to spending on self-medication.

\begin{tabular}{|c|c|c|c|}
\hline \multicolumn{2}{|c|}{ Healthcare Type } & \multicolumn{2}{|c|}{ Health expenditure in INR@ } \\
\hline & & Urban & Rural \\
\hline \multirow[t]{2}{*}{ Total In patient care } & Mean & 5766.15 & 3812.16 \\
\hline & SD & 8673.27 & 8761.43 \\
\hline \multirow[t]{2}{*}{ Outpatient care } & Mean & 1097.87 & 962.29 \\
\hline & SD & 1009.08 & 1080.89 \\
\hline \multirow[t]{2}{*}{ Outpatient dental } & Mean & 189.73 & 504.14 \\
\hline & SD & 466.21 & 2096.95 \\
\hline \multirow[t]{2}{*}{ AYUSH } & Mean & 258.78 & 240.67 \\
\hline & SD & 431.34 & 368.762 \\
\hline \multirow[t]{2}{*}{ Self-medication } & Mean & 28.22 & 34.10 \\
\hline & SD & 40.48 & 64.02 \\
\hline \multirow[t]{2}{*}{ Medical aid } & Mean & 235.04 & 186.84 \\
\hline & SD & 445.04 & 358.46 \\
\hline Total & Mean & 7842.25 & 6034.82 \\
\hline
\end{tabular}

Table 2: Morbidity pattern among the elderly by their residential status and gender $(n=404)$.

Table 3 show the different forms of healthcare services availed by elderly. Most frequent healthcare services type availed was out patient allopathic care (62.9\%), followed by AYUSH care (36.4\%). Use of AYUSH care was more prevalent among the elderly residing in rural areas as compared to urban ones. A significant proportion (35.6\%) of the elderly self-medicated themselves. 
Page 5 of 6

\begin{tabular}{|l|l|l|l|}
\hline & SD & 9067.97 & 9566.45 \\
\hline \multicolumn{2}{|l|}{$@$ Indian National Rupees (1 US \$ = 65 INR ) } \\
\hline
\end{tabular}

Table 4: Distribution of OOP expenditure by the type of healthcare services availed.

\section{Discussion}

\section{Morbidities in elderly}

We interviewed a total of 404 elderly participants in the present study. In our study proportion of the elderly having one or more chronic and acute diseases was $56.9 \%$ and $23.0 \%$ respectively. Most frequent single chronic disease entity among all study participants was hypertension $(20.5 \%)$, and the most common group of morbidities were dental (18.8\%), orthopedics $(17.3 \%)$ and cardiovascular $(11.8 \%)$ in that order.

\section{Healthcare utilization}

In our study the proportion of those utilizing Inpatient care, outpatient care, Outpatient dental care, AYUSH care, and self-Medication was $32.9 \%, 62.9 \%, 20.7 \%, 36.4 \%$ and $35.6 \%$ respectively. In a study conducted by Brinda EM, et al. in South India, the proportion of visits to allopathic health care, alternative medical care facilities (including Homeopathy, Siddha, Ayurveda and Unani) and dentists, were $42.0 \%$, $4.0 \%$ and $5.0 \%$ respectively [16]. A considerable proportion (36.4\%) of the population used AYUSH system. It can be because of many reasons. Firstly there is abundance of AYUSH practitioners in Lucknow, secondly the overall cost of treatment is less as compared to allopathic care. In our study of the total elderly $35.6 \%$ self-medicated themselves. Most of those who self-medicated themselves were poor and got medicine directly from the medical store without any prescription from doctor. This is a worry some trend as few medicines just cure symptoms, not the disease itself which remain untreated, progresses and lead to complications.

\section{Out of pocket expenditure}

Total mean OOP expenditure on health among participants from urban and rural area was INR 7842.25 (SD 9067.97) and INR 6034.82 (SD 9566.45) respectively. Brinda et al. [16] in their study observed that the mean total out-of-pocket health expenditure over the previous three months was INR 216. The mean expenditure on visiting traditional healers was the highest with INR 78, followed by the expenditure on private physicians, INR 60 [15]. Such huge difference between our studies can be due to two reasons. One that two studies were conducted about 12 years apart and secondly later study included patients from rural areas only.

In our study expenditure on in-patient care was INR 5766.15 and INR 3812.16 in urban and rural areas respectively. As per NSSO (2005) the total expenditure for hospitalization for urban and rural person was INR 9,367 and 6,225 respectively. Similar to our study NSSO also reported that the medical expenditure proper per hospitalization case were almost 50 per cent higher in the urban areas than in the rural areas [17]. In our study expenditure on outpatient medical care was INR 1097.87 and INR 962.29 in urban and rural areas respectively.

\section{Limitation}

Only those elderly whose name was in the voter list could have the chance of being enrolled in the study. Because of recall bias, there were chances of both underreporting and over reporting of the incurred expenditure, but we tried to minimize it by crosschecking/verifying the amount by the bills and prescription slip in all cases that we can.

\section{Conclusion}

In conclusion, it should be pointed out that burden of out of health expenditure on Indian citizens is worrisome. But it the degree to which out of pocket expenditure exceeds the national level among the geriatrics age group population is more troublesome. Young people can compensate for healthcare expenditure but elderly, many of whom are economically dependent on others cannot arrange for this expenditure. The proportion of the elderly in India and the world is growing continuously and thus, all governments should develop a scheme to provide financial security to all the elderly so that they can live the remaining of their life with dignity.

\section{Conflict of Interest}

No potential conflicts of interest were declared.

\section{Acknowledgment}

Authors are sincerely thankful to Prof. Uday Mohan and Dr. Moneer Alam for their guidance and motivation that they provided in going forward and consummating this work. Our sincere thanks to all the elderly participants who had the patience to sit and heedfully discern all our questions and queries and answering them to the best of their cognizance.

\section{Funding/Financial support}

None received

\section{Author Contributions}

Dr. S K Singh is responsible for the study concept and design of protocol, designed the study questionnaire, cross checked filled questionnaire, final proof reading of manuscript. Dr. P Pandey is responsible for the Data collection, data entry, data analysis, preparation of manuscript.

\section{References}

1. World Health Day 2012.

2. National Health Policy for Senior Citizens 2011.

3. UN world ageing report 2013.

4. SRS Statistical Report 2012.

5. Prakash R, Chaudhary SK, Singh UC (2004) A Study Of Morbidity Pattern Among Geriatric Population in an Urban Area of Udaipur, Rajasthan. Indian Journal of Community Medicine 29: 35.

6. Bhatia SPS, Swami HM, Thakur JS, Bhatia VA (2007) Study of Health Problems and Loneliness among the Elderly in Chandigarh. Indian Journal of Community Medicine 32: 255-258.

7. Gupta A, Mohan U, Tiwari SC, Singh SK, Singh VK (2014) Dimensions and determinants of quality of life among senior citizens of Lucknow, India. Int J Med Public Health 4: 477-81.

8. Ministry of AYUSH. 
Citation: $\quad$ Singh SK, Pandey P (2016) Morbidity Profile, Healthcare Utilization and Associated out of Pocket Expenditure on Health among Elderly Population of Lucknow District, Northern India . Trop Med Surg 4: 210. doi:10.4172/2329-9088.1000210

Page 6 of 6

9. Out of pocket expenditure.

10. World health statistics 2013.

11. Government of India (2005) National health accounts India 2001-02. Ministry of Health and Family Welfare, New Delhi.

12. Misra S, Awasthi S, Singh JV, Agarwal M, Kumar V (2013) Estimation of out of pocket direct and indirect medical expenditure and spending burden ratio across income quintiles in urban Lucknow, India. Clinical Epidemiology and Global Health 1: 12-18.

13. Sample Registration System- Statistical Report 2012.
14. Legislative assembly in Lucknow district.

15. The schedule 60_25.0 NSSO.

16. Brinda EM, Rajkumar AP, Enemark U, Prince M, Jacob KS (2012) Nature and determinants of out-of-pocket health expenditure among older people in a rural Indian community. International Psychogeriatrics 24: 1664-73.

17. National Sample Survey Organization (NSSO) (2006) Morbidity healthcare and the condition of aged Report No 507, Ministry of Statistics and Programme Implementation, New Delhi. 